\title{
Potential natural inhibitors of xanthine oxidase and HMG-CoA reductase in cholesterol regulation: in silico analysis
}

Rishab Marahatha ${ }^{1}$, Saroj Basnet ${ }^{2}$, Bibek Raj Bhattarai ${ }^{1}$, Prakriti Budhathoki ${ }^{1}$, Babita Aryal', Bikash Adhikari ${ }^{1}$, Ganesh Lamichhane ${ }^{1}$, Darbin Kumar Poudel ${ }^{1}$ and Niranjan Parajuli ${ }^{1 *^{*}}$

\begin{abstract}
Background: Hypercholesterolemia has posed a serious threat of heart diseases and stroke worldwide. Xanthine oxidase $(\mathrm{XO})$, the rate-limiting enzyme in uric acid biosynthesis, is regarded as the root of reactive oxygen species (ROS) that generate atherosclerosis and cholesterol crystals. $\beta$-Hydroxy $\beta$-methylglutaryl-coenzyme A reductase (HMGR) is a rate-limiting enzyme in cholesterol biosynthesis. Although some commercially available enzyme inhibiting drugs have effectively reduced cholesterol levels, most of them have failed to meet potential drug candidates' requirements. Here, we have carried out an in-silico analysis of secondary metabolites that have already shown good inhibitory activity against $X O$ and HMGR in a wet lab setup.
\end{abstract}

Methods: Out of 118 secondary metabolites reviewed, sixteen molecules inhibiting XO and HMGR were selected based on the $I C_{50}$ values reported in in vitro assays. Further, receptor-based virtual screening was carried out against secondary metabolites using GOLD Protein-Ligand Docking Software, combined with subsequent post-docking, to study the binding affinities of ligands to the enzymes. In-silico ADMET analysis was carried out to explore their pharmacokinetic properties, followed by toxicity prediction through ProTox-II.

Results: The molecular docking of amentoflavone (GOLD score 70.54, $\Delta \mathrm{G}_{\text {calc. }}=-10.4 \mathrm{Kcal} / \mathrm{mol}$ ) and ganomycin I (GOLD score 59.61, $\Delta \mathrm{G}_{\text {calc. }}=-6.8 \mathrm{Kcal} / \mathrm{mol}$ ) displayed that the drug has effectively bound at the competitive site of $\mathrm{XO}$ and HMGR, respectively. Besides, 6-paradol and selgin could be potential drug candidates inhibiting XO. Likewise, n-octadecanyl-O-a-D-glucopyranosyl ( $6^{\prime} \rightarrow$ 1"')-O-a-D-glucopyranoside could be potential drug candidates to maintain serum cholesterol. In-silico ADMET analysis has shown that these sixteen metabolites were optimal within the categorical range compared to commercially available XO and HMGR inhibitors, respectively. Toxicity analysis through ProTox-II revealed that 6-gingerol, ganoleucoin $\mathrm{K}$, and ganoleucoin $\mathrm{Z}$ are toxic for human use.

Conclusion: This computational analysis supports earlier experimental evidence towards the inhibition of $X O$ and HMGR by natural products. Further study is necessary to explore the clinical efficacy of these secondary molecules, which might be alternatives for the treatment of hypercholesterolemia.

Keywords: Natural products, Molecular docking, Cholesterol, Enzyme inhibition

\footnotetext{
* Correspondence: nparajuli@cdctu.edu.np

${ }^{1}$ Central Department of Chemistry, Tribhuvan University, Kirtipur, Kathmandu, Nepal

Full list of author information is available at the end of the article
}

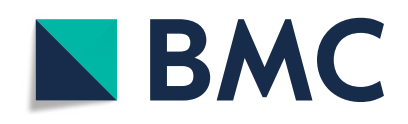

(- The Author(s). 2021 Open Access This article is licensed under a Creative Commons Attribution 4.0 International License, which permits use, sharing, adaptation, distribution and reproduction in any medium or format, as long as you give appropriate credit to the original author(s) and the source, provide a link to the Creative Commons licence, and indicate if changes were made. The images or other third party material in this article are included in the article's Creative Commons licence, unless indicated otherwise in a credit line to the material. If material is not included in the article's Creative Commons licence and your intended use is not permitted by statutory regulation or exceeds the permitted use, you will need to obtain permission directly from the copyright holder. To view a copy of this licence, visit http://creativecommons.org/licenses/by/4.0/. The Creative Commons Public Domain Dedication waiver (http://creativecommons.org/publicdomain/zero/1.0/) applies to the data made available in this article, unless otherwise stated in a credit line to the data. 


\section{Background}

Globally, ischemic heart disease (IHD) is the foremost cause of cardiovascular diseases (CVDs) followed by stroke [1]; also, high cholesterol level is accountable for one-third of all cases of IHD and increased risks of stroke too [2]. Cholesterol acquired via de novo synthesis $(600-900 \mathrm{mg} /$ day) \& diet (300-500 mg/day), transported via blood, and excreted through bile acid biosynthesis (500-600 mg/day) and as biliary cholesterol (600 mg/day) are the major aspects of its homeostasis in human [3, 4]. Several elements, such as age, gender, human genetics, dietary habits, physical activity, and metabolic disorder, have affected cholesterol levels [5]. Nonetheless, various epidemiological studies have recently confirmed that plasma cholesterol levels are correlated with many bacterial gut microbiomes [6]. Cholesterol is an indispensable structural component of the cell membrane and serves as the substrate for biosyntheses of vitamin D, bile acids, and steroid hormones [7]. However, its accumulation in the body is associated with atherosclerosis, hypertension, and ultimately to CVDs, which have resulted in increased mortality and morbidity rates globally $[1,8]$. Whence, from a therapeutic point of view, the regulations of total serum cholesterol and triglycerides have gained much heed against hyperlipidemia [9].

Statins, competitive inhibitors of HMGR, are the widely recognized medication to lower cholesterol levels [10, 11]. Other available medications include ezetimibe (cholesterol absorption and Niemann-Pick C1-like protein inhibitor) and bile acid sequestrants (induce hepatic conversion of cholesterol into bile acids) $[12,13]$. Lomitapide (microsomal triglyceride transfer protein inhibitor), mipomersen (apolipoprotein B 100 inhibitor), alirocumab \& evolocumab (proprotein convertase subtilisin kexin type 9 (PCSK9) inhibitors), and bempedoic acid (adenosine triphosphate-citrate lyase inhibitor) are the latest approved remedy against hypercholesterolemia in the last decades [14-16]. Moreover, the inhibitors of acyl-CoA cholesterol acyltransferase 2 (ACAT2), diglyceride acyltransferase 2 (DGAT-2), high-density lipoproteins (HDL) modulating drugs, small interfering RNA (inclisiran), and angiopoietin-like protein 3 (ANGPTL3) are under progress for clinical trials in human. They could be prospective in lowering cholesterol levels $[11,17]$.

$\mathrm{XO}(290 \mathrm{kDa})$ is involved in uric acid biosynthesis and is regarded as the root of $\operatorname{ROS}\left(\mathrm{H}_{2} \mathrm{O}_{2}\right.$ and $\left.\mathrm{O}_{2}^{-}\right)$in vascular tissue and, hence engenders atherosclerosis [18-20]. It is the rate-limiting enzyme involved in the catabolism of purine nucleotides, the step that oxidizes xanthine to uric acid [21, 22]. IHD correlates with upraised uric acid levels, and XO inhibitors such as allopurinol and febuxostat have palliated the risk of IHD by minimizing the effect of ROS and enhancing endothelial function and ATP synthesis in ischaemic tissue [23, 24]. Elevated cholesterol level increases the activity of $\mathrm{XO}$ that causes oxidative stress in tissue and decreases the activity of nitric oxide synthase (NOS) that surges CVDs risks [25, 26]. This oxidative stress converts low-density lipoprotein (LDL) to oxidized LDL, which is absorbed by macrophages in the intima of the vascular wall that eventually forms cholesterol crystals and deteriorates endothelial function [27, 28]. In cholesterol biosynthesis, the conversion of acetyl CoA to HMG-CoA is catalyzed by HMGR (200 kDa) found in the endoplasmic reticulum (ER) [29, 30]. It is the rate-limiting enzyme involved in the synthesis of mevalonate, while the post-squalene portions are regulated by cytochrome P450 51 [3].

The mechanisms, pharmacokinetics, interactions, and side effects of the drugs, as mentioned above, are well explained by Fein gold [31]. On account of side effects, it is challenging to explore new drugs of high medicinal importance. In this study, we have focused on potential HMGR and $\mathrm{XO}$ inhibitors, based on natural products, which are considered as the wellspring of biologically and pharmacologically active sources of secondary metabolites [32, 33]. We have performed virtual screenings of some secondary metabolites showing good inhibitory activity with the aid of computer-based computation. In-silico ADMET analysis, which would lower the use of animal testing following ethical guidelines in the pharmacological experiment, were studied using the pKCSM web application. Furthermore, toxicity analysis through ProTox-II and molecular docking using GOLD Protein-Ligand Docking Software combined with subsequent post-docking were carried out to uncover further evidence on the inhibition mechanism. We believe that our findings would be beneficial in drug development programs concerning hypolipidemic agents.

\section{Methods}

\section{Selection of XO and HMGR}

The crystal structures of XO (PDB ID:1N5X, 2.80 ̊) and HMGR (PDB ID:1HWK, $2.22 \AA$ ) were obtained from Protein Data Bank (PDB) [34] and were chosen for their availability as refined crystal structures, which were confirmed by X-ray diffraction [35] [29]. The crystal structure of XO, complexed with febuxostat, was retrieved to understand the protein-ligand docking algorithm and to predict the position of metabolites in the binding cavity of XO. The structure of XO was a homodimer (chain A and B), where only chain A was used for docking studies. Similarly, the dimeric crystal structure of HMGR, complexed with atorvastatin, was used for docking studies where two neighboring monomers were relevant for making interactions with statins [35, 36]. Other chains and water molecules were removed using MOE protein preparation wizard [37].

\section{Designing of ligands}

The data set was prepared based on an extensive literature survey taking $\mathrm{IC}_{50}$ values of in-vitro enzyme inhibition assays against $\mathrm{XO}$ and HMGR by various secondary 
metabolites. Based on $\mathrm{IC}_{50}$ values, sixteen plant- and fungus-based secondary metabolites (Tables 1 and 2) were chosen for the ligand-protein docking study. The docking study was performed against commercial drugs such as atorvastatin, simvastatin, lovastatin, and pravastatin for HMGR. On the other hand, commercial drugs such as allopurinol, febuxostat, topiroxostat, and probenecid were used for molecular docking studies with XO. The structures of the ligand molecules and the control drugs of both enzymes were retrieved from the PubChem database [38] and verified from SciFinder. The structures were retrieved in SDF format and were converted to PDB and MOL2 format using Discovery Studio Visualizer 4.0 software. The structure and complete chemical properties, torsional energy, van der Waals potential energy, electrostatic energy, weight, $\log P$, total polar surface area (TPSA), donor atoms, and acceptor atoms of the ligands were listed (Supplementary Table 4S) by the help of MOE Module [39].

\section{Prediction of active sites}

Amino acids involved in active pocket formation were determined using Site-Finder (Supplementary Table 3S), which calculates possible active sites in a receptor from the 3D atomic coordinates based on alpha shape methodology [40]. All the amino acid residues were listed adequately from the active site analysis and validated from published crystal structure active residues and published research journals for complete study [41, 42].

\section{Computational analysis}

Flexible docking simulations were performed using GOLD [43] to investigate the molecules' binding modes to predict the efficiency of secondary metabolites to inhibit HMGR and $\mathrm{XO}$ enzymes. These novel potential compounds were obtained from the extensive literature review and deposited in the inbuilt CHEM-TU Natural Metabolites Library. Genetic algorithms had been used in GOLD that had integrated fully- and partially- ligand flexibility docking approaches in the neighborhood of the protein's active site [44] to determine the appropriate binding positions, orientations, and conformations of ligands [45]. All other parameters were maintained as default. In the flexible docking process and according to the GOLD score molecular mechanics function, the ligand with the highest fitness GOLD score was deemed to have the highest binding affinity. The function was expressed as,

$$
\begin{aligned}
& \text { GOLD Fitness }=\text { Shb_ ext }+1.375\left(\text { Svdw }_{-} \text {ext }\right) \\
& \left.+\mathrm{Shb}_{-} \text {int }+\mathrm{Svdw}_{-} \text {int }\right)
\end{aligned}
$$

Where Shb_ext is the protein-ligand hydrogen-bond score, and Svdw_ext is the protein-ligand van der Waals score. Shb_int contributes to fitness due to intramolecular hydrogen bonds in the ligand, Svdw_int is the contribution due to intermolecular strain in the ligand. The details about molecular docking results are mentioned in Supplementary Table 1S.

\section{Estimation of binding energy}

We applied a semi-empirical method in-built to AutoDock Vina [46]. The prediction of absolute binding energies may be less accurate than more computationally expensive, purely force field-based methods, but this semiempirical approach is considered well-suited for the relative rankings [47]. The $\mathrm{pIC}_{50}$ value was calculated using formula: pIC50 $=-\log \left(\mathrm{IC} 50^{*} 10^{-9}\right)$ and $\Delta \mathrm{G}_{\text {Experimental was }}$ calculated by the equation: $\Delta \mathbf{G}_{\text {Exp. }}=-\mathrm{RT} \ln \left(\mathrm{pIC}_{50}\right)$ [48].

\section{Prediction of ADMET profiles}

Drug discovery programs assisted analysis of absorption, distribution, metabolism, excretion, and toxicity (ADME $\mathrm{T}$ ) properties of secondary metabolites. The potential pharmacokinetic properties prediction was completed using the pKCSM web application [49]. In-silico potential toxicity of secondary metabolites was assessed by ProTox-II, which was based on toxic, lethal dose $\left(\mathrm{LD}_{50}\right)$ value ranging from class 1 and 2 (fatal), class 3 (toxic), class 4 and 5 (harmful), while class-6 (non-toxic) [50]. The confidence score of secondary metabolites for specific targets had been used to predict the reliability of toxicity based on the value of more than 0.7 [51].

\section{Results}

In the beginning, a dataset was prepared based on a literature review taking $\mathrm{IC}_{50}$ values of in-vitro enzyme inhibition assays with HMGR and XO by natural products. In this article, Supplementary Table $2 S$ provides details about the targets and their description. Figure 1 presents the structure of secondary metabolites and natural sources, which were used in this study. Tables 1 and 2 give GOLD fitness scores and hydrogen bonding interaction values between targets and secondary metabolites, interaction type, and bond length of the docking. The 2D and 3D interactions of the high GOLD scoring metabolites and commercial drugs with the target enzymes were shown in Figs. 2 and 3 and Supplementary Figs. (1S, 2S, 3S, 4S, 5S, 6S, 7S). The molecular properties of commercial drugs and selected secondary metabolites were shown in Supplementary Table 4S. Supplementary Table $11 \mathrm{~S}$ and $12 \mathrm{~S}$ illustrates the theoretical (calculated) and experimental binding energy of secondary metabolites.

\section{Molecular docking of ligands into XO}

From the molecular docking, we observed electrostatic 2D and 3D molecular surfaces (Fig. 2); the study showed that amentoflavone (1) and 6-paradol (3) were well located into the active site of XO with the GOLD fitness 


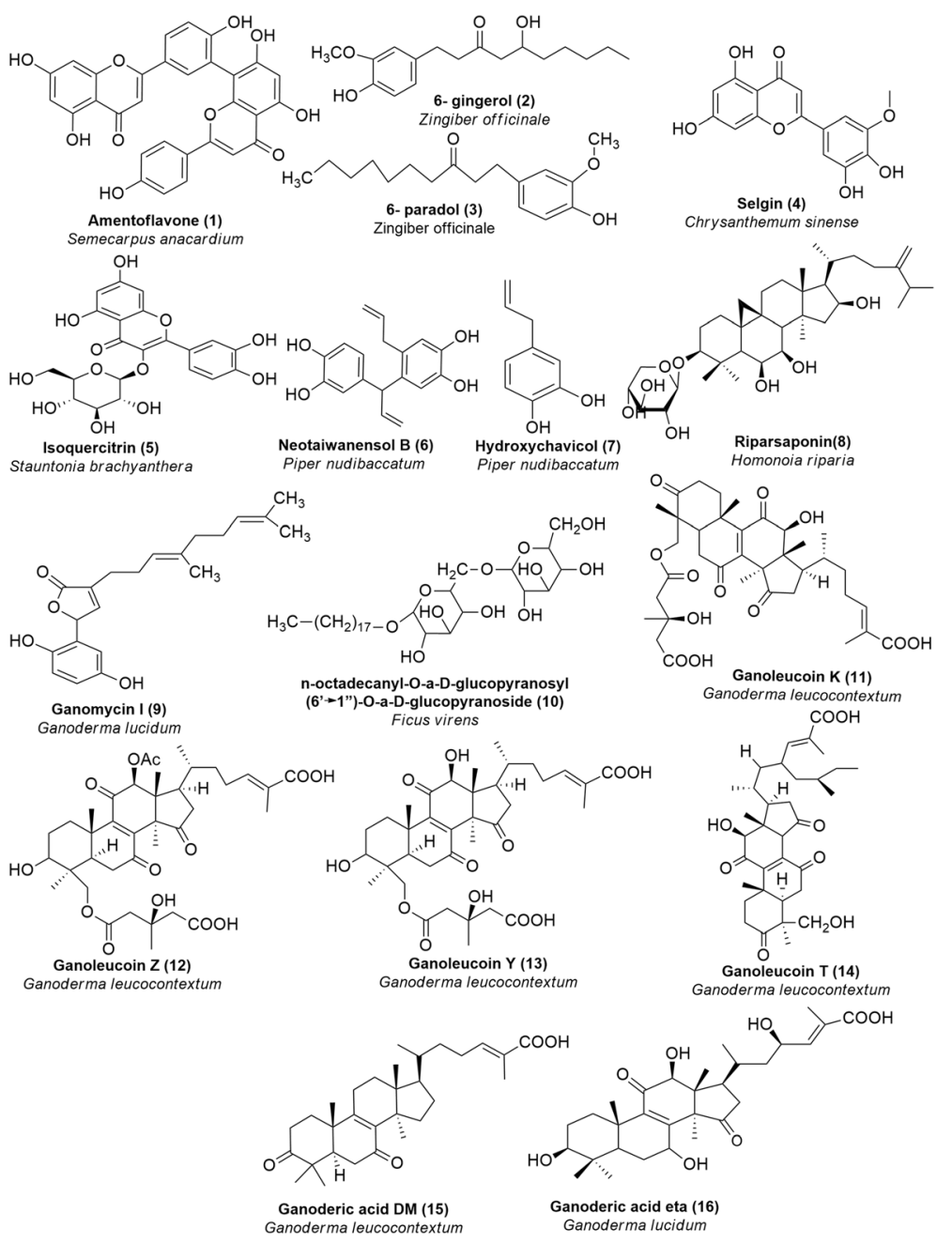

Fig. 1 Plant and fungus-based secondary metabolites inhibiting XO (1-8) and HMGR (9-16)

score of 70.54 and 67.34 (Table 1 ) respectively which is higher than commercial drugs febuxostat (GOLD score 64.53), topiroxostat (GOLD score 61.46), probenecid (GOLD score 57.75), and allopurinol (GOLD score 46.16) (Supplementary Table 10S).

Similarly, selgin (4), isoquercitrin (5), neotaiwanesol B (6), and hydroxychavicol (7) have shown satisfactory interactions with the active site residues with fitness score of $61.41,55.4,52.77$, and 49.02, respectively.

Amino acid residues participating in forming $\mathrm{Pi}-\mathrm{Pi}$ and Pi-cation interactions were also investigated. Amentoflavone (1) and 6-paradol (3) was surrounded by several amino acid residues (Glu 802, Asn 768, Phe 914, ser 876, and Arg 880), which were described as active site residues [52]. It has been reported that Arg 880 and Glu 802 residues play a crucial role in the hydroxylation of substrate xanthine [53]. Hydrogen bonding with Glu 802 residue for a top-scoring amentoflavone (1) and Arg 880 for commercial drugs (febuxostat) was observed with the bond lengths of $2.1 \AA$ and $3.0 \AA$, respectively. Nevertheless, 6-paradol (3), selgin (4), and isoquercitrin (5) also showed significant interactions through $\mathrm{H}$-bonding within the range of $2-3.2 \AA$ as well as Pi-Pi interaction with Phe 914 of target XO protein.

\section{Molecular docking of ligands into HMGR}

Figure 3 showed the 2D and 3D molecular surface's orientation of the top-scored secondary metabolites ganomycin I (9) and n-octadecanyl-O- $\alpha-\mathrm{D}$-glucopyranosyl $\left(6^{\prime} \rightarrow 1^{\prime \prime}\right)$-O- $\alpha$-D-glucopyranoside (10). The study has shown that ganomycin I (9) bound competitively into the active site of HMGR with the GOLD fitness score of 59.61 (Table 2), higher than commercial drugs simvastatin (GOLD fitness score 56.81), lovastatin (GOLD fitness score 41.36), and pravastatin (GOLD fitness score 54.83) (Supplementary Table 10S). Similarly, n-octadecanyl-O- $\alpha$-D-glucopyranosyl $\left(6^{\prime} \rightarrow 1^{\prime \prime}\right)-O-\alpha-D$ glucopyranoside (10) has shown satisfactory interactions 
Table 1 GOLD Fitness score and Protein-Ligand Interactions of Protein ID: 1N5X with XO Inhibitors

\begin{tabular}{|c|c|c|c|c|c|}
\hline Compounds & Reported $\mathrm{IC}_{50}$ value $(\mu \mathrm{M})$ & GOLD Score & H-Bond Interaction Residues & Bond Length & Other Interacting Residues \\
\hline Amentoflavone (1) & 0.09 & 70.54 & $\begin{array}{l}\text { Glu } 802 \\
\text { Asn } 768 \\
\text { Phe } 914 \\
\text { Ser } 876\end{array}$ & $\begin{array}{l}2.1 \\
2.7 \\
- \\
2.8\end{array}$ & Pi-Pi interaction with Phe 914 \\
\hline 6- Gingerol (2) & 10.50 & 68.75 & $\begin{array}{l}\text { Thr } 1010 \\
\text { Ala } 1079 \\
\text { Phe } 798 \\
\text { Phe } 914\end{array}$ & $\begin{array}{l}1.9 \\
2.4 \\
2.5 \\
-\end{array}$ & Pi-Pi interaction with Phe 914 \\
\hline 6- Paradol (3) & 12.40 & 67.34 & $\begin{array}{l}\text { Arg } 880 \\
\text { Phe } 914\end{array}$ & $\begin{array}{l}3.2 \\
-\end{array}$ & Pi-Pi interaction with Phe 914 \\
\hline Selgin (4) & 0.22 & 61.41 & $\begin{array}{l}\text { Phe } 914 \\
\text { Glu } 1261 \\
\text { Thr } 1010 \\
\text { Arg } 880\end{array}$ & $\begin{array}{l}- \\
2.0 \\
3.0 \\
2.4 / 3.2\end{array}$ & Pi-Pi interaction with Phe 914 \\
\hline Isoquercitrin (5) & 1.60 & 55.4 & $\begin{array}{l}\text { Thr1010 } \\
\text { Ala } 1079 \\
\text { Phe } 914 \\
\text { Ser } 876 \\
\text { Asp } 872 \\
\text { Asn } 768 \\
\text { Lys } 771\end{array}$ & $\begin{array}{l}2.90 / 3.003 .00 \\
2.8 \\
- \\
2.9 \\
3 \\
2.5\end{array}$ & Pi-Pi interaction with Phe 914 \\
\hline Neotaiwanensol B (6) & 0.28 & 52.77 & $\begin{array}{l}\text { Ser } 876 \\
\text { Thr } 1010 \\
\text { Arg } 880 \\
\text { Phe } 914\end{array}$ & $\begin{array}{l}3 \\
1.6 \\
2.90 / 2.90 \\
2.9\end{array}$ & Pi-Pi interaction with Phe 914 \\
\hline Hydroxychavicol (7) & 0.38 & 49.02 & $\begin{array}{l}\text { Arg } 880 \\
\text { Phe } 914\end{array}$ & $\begin{array}{l}2.9 / 2.7 \\
-\end{array}$ & Pi-Pi interaction with Phe 914 \\
\hline Riparsaponin (8) & 0.01 & 27.92 & Leu 648 & 3.2 & No any extra interaction \\
\hline
\end{tabular}

with the active site residues with fitness scores of 52.69 . Arg A590 amino acid was involved in forming Pi-cation interaction with ganomycin I (9) with unique features of high Vander Waals energy 32.11 (Supplementary Table 4S). In commercial drugs, other active residues (Arg A590, Ser A684, Gly A692, Lys A691, Asp A690, Glu B559, Lys B735) were involved in forming hydrogen bonds as wells as in Pi-Pi interactions. Furthermore, ganoleucoin $\mathrm{T}$ (14), ganoderic acid DM (15), and ganoderic acid $\eta$ (16) were found interacting with target protein amino acid residues via $\mathrm{H}$-bonds ranging 1.3-3.3 $\AA$ (Fig. 3).

\section{Analysis of binding energy}

The relationship between different variables like binding free energies (theoretical and experimental), $\mathrm{IC}_{50}$, and $\mathrm{pIC}_{50}$ of secondary metabolites for both $\mathrm{XO}$ and HMGR was studied. For XO, there is a positive (direct) relationship between theoretical and experimental binding energy (low degree: 0.198); experimental binding energy and $\mathrm{IC}_{50}$ (high degree: 0.869 ), and a negative (inverse) relationship between theoretical binding energy and $\mathrm{pIC}_{50}$ (low degree: - 0.186); experimental binding energy and $\mathrm{pIC}_{50}$ (high degree: - 0.998) and between $\mathrm{IC}_{50}$ and $\mathrm{pIC}_{50}$ (high degree: 0.840). Similarly, for HMGR, there is a negative (inverse) relationship between theoretical and experimental binding energy and $\mathrm{pIC}_{50}$ (high degree: -0.999 ); $\mathrm{IC}_{50}$ and $\mathrm{pIC}_{50}$ (high degree: -0.739 ) and a positive (direct) relationship between experimental binding energy; $\mathrm{IC}_{50}$ (high degree: 0.762 ) and between theoretical binding energy and $\mathrm{pIC}_{50}$ (moderate: 0.525).

\section{Analysis of ADMET profiles}

Supplementary Table 8S (a) and (b) showed the detail of the ADMET analysis of sixteen metabolites. Compounds (1)-(9) and (14)-(16) were significantly absorbed, while (10)-(13) were found to be poorly absorbed in the human small intestine. However, these metabolites could not cross blood-brain barriers (BBB) readily, and none of this inhibited CYP3A4 and CYP2D6. Utterly, all the metabolites showed low hepatic and renal clearance. According to the in-silico toxicity prediction through Protox-II, compounds (14) and (16) were non-toxic while compounds (3), (4), (5), (8), (1), (6), (7), (9), (10), and (15) were classified under the harmful category. Compounds (2), (11), (12), and (13) were found to be toxic for human use. Moreover, Supplementary Table 7S showed the detail of predicted $\mathrm{LD}_{50}$ values and confidence scores of specific active targets of each metabolite. This analysis showed that all sixteen metabolites except (2), (11), (12), and (13) were optimal within the categorical range compared to commercially available $\mathrm{XO}$ and HMGR inhibitors, respectively. 
Table 2 GOLD Fitness score and Protein-Ligand Interactions of Protein ID: 1HWK with HMGR Inhibitors

\begin{tabular}{|c|c|c|c|c|c|}
\hline Compounds & $\begin{array}{l}\text { Reported } I C_{50} \\
\text { value }(\mu \mathrm{M})\end{array}$ & $\begin{array}{l}\text { GOLD } \\
\text { Score }\end{array}$ & $\begin{array}{l}\text { H-Bond Interaction } \\
\text { Residues }\end{array}$ & $\begin{array}{l}\text { Bond Length } \\
(\AA)\end{array}$ & $\begin{array}{l}\text { Other Interacting } \\
\text { Residues }\end{array}$ \\
\hline Ganomycin I (9) & $12.3 \pm 1.7$ & 59.61 & Arg A590 & - & $\begin{array}{l}\text { Pi-cation interaction } \\
\text { with Arg A590 }\end{array}$ \\
\hline $\begin{array}{l}\text { n-octadecanyl-O-a-D-glucopyranosyl(6' } \rightarrow \text { 1")-O-a-D- } \\
\text { glucopyranoside (10) }\end{array}$ & 0.164 & 52.69 & $\begin{array}{l}\text { Lys A691 } \\
\text { Gly B560 } \\
\text { Lys B735 } \\
\text { Arg A590 } \\
\text { Asp A690 }\end{array}$ & $\begin{array}{l}3.1 \\
2.8 \\
3.2 \\
2.9 \\
1.7 / 3.3\end{array}$ & $\begin{array}{l}\text { No any extra } \\
\text { interaction }\end{array}$ \\
\hline Ganoleucoin K (11) & $10.7 \pm 2.9$ & 43.91 & $\begin{array}{l}\text { Asn A658 } \\
\text { Val A805 }\end{array}$ & $\begin{array}{l}2.5 \\
2.4\end{array}$ & $\begin{array}{l}\text { No any extra } \\
\text { interaction }\end{array}$ \\
\hline Ganoleucoin Z (12) & $8.68 \pm 0.96$ & 43.41 & $\begin{array}{l}\text { Lys A691 } \\
\text { Asp A690 } \\
\text { Arg A590 } \\
\text { Lys B735 } \\
\text { Leu B857 }\end{array}$ & $\begin{array}{l}2.8 \\
2.10 / 3.30 \\
2.7 \\
3.1 \\
2.2\end{array}$ & $\begin{array}{l}\text { No any extra } \\
\text { interaction }\end{array}$ \\
\hline Ganoleucoin Y (13) & $9.72 \pm 0.91$ & 30.85 & $\begin{array}{l}\text { Asn A658 } \\
\text { Ser A661 }\end{array}$ & $\begin{array}{l}2.6 \\
2.3\end{array}$ & $\begin{array}{l}\text { No any extra } \\
\text { interaction }\end{array}$ \\
\hline Ganoleucoin T (14) & $10.3 \pm 1.78$ & 29.15 & $\begin{array}{l}\text { Asp A690 } \\
\text { Gly B560 } \\
\text { Thr B558 }\end{array}$ & $\begin{array}{l}1.3 \\
3.2 \\
2.2\end{array}$ & $\begin{array}{l}\text { No any extra } \\
\text { interaction }\end{array}$ \\
\hline Ganoderic acid DM (15) & $9.5 \pm 1.5$ & 18.89 & $\begin{array}{l}\text { Arg A590 } \\
\text { Asn B755 }\end{array}$ & $\begin{array}{l}2.7 \\
3.0\end{array}$ & $\begin{array}{l}\text { No any extra } \\
\text { interaction }\end{array}$ \\
\hline Ganoderic acid $\eta$ (16) & $29.8 \pm 1.5$ & 12.13 & $\begin{array}{l}\text { Arg A590 } \\
\text { Lys A692 } \\
\text { Lys B735 }\end{array}$ & $\begin{array}{l}2.5 \\
2.9 \\
2.8\end{array}$ & $\begin{array}{l}\text { No any extra } \\
\text { interaction }\end{array}$ \\
\hline
\end{tabular}

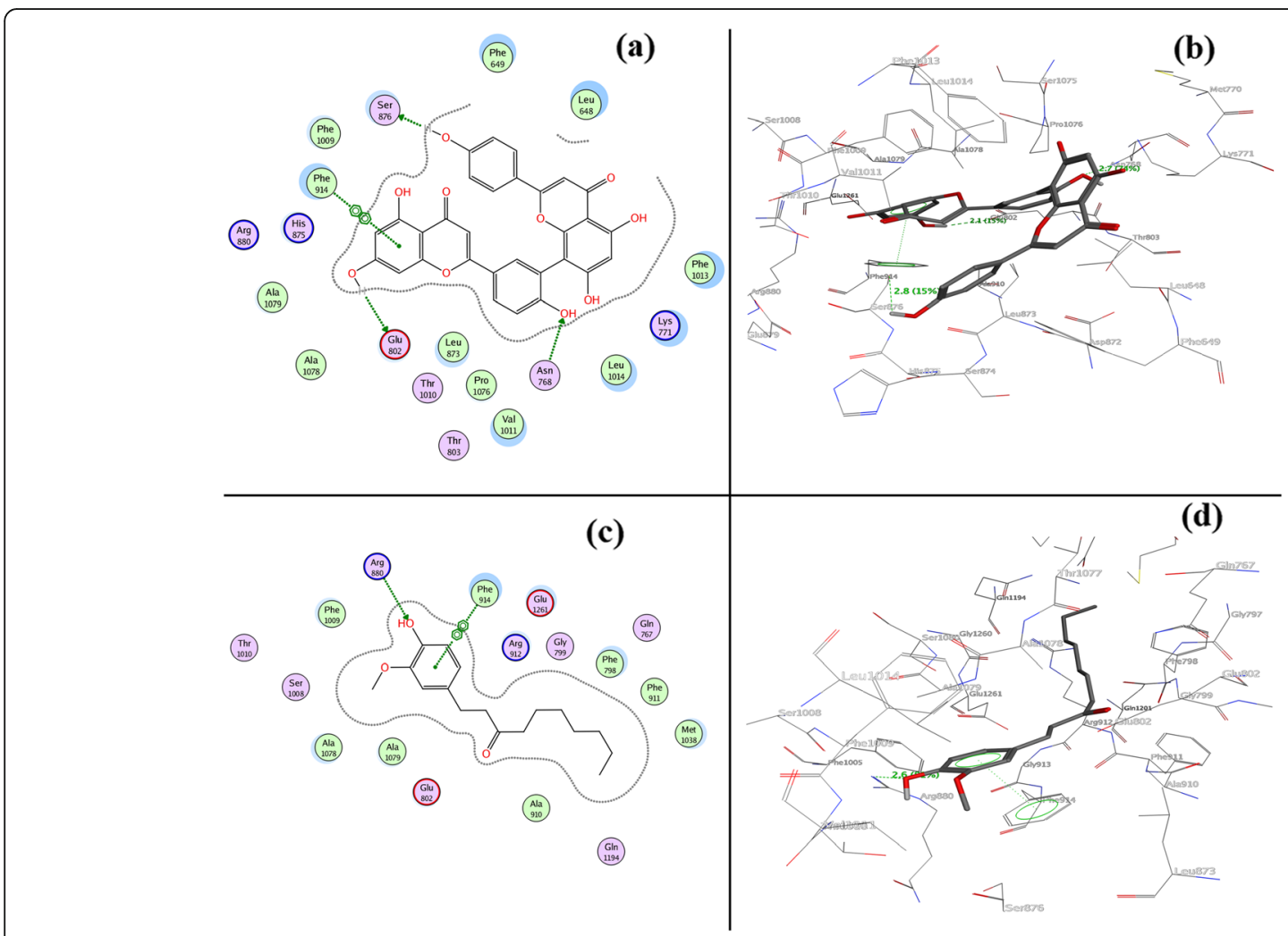

Fig. 2 a $2 D$ and $\mathbf{b} 3 D$ interactions of $X O$ with amentoflavone (1) (GOLD fitness score of 70.54); c 2D and $\mathbf{d}$ 3D (lower) interactions of XO with 6gingerol (2) (GOLD fitness score of 68.75) 


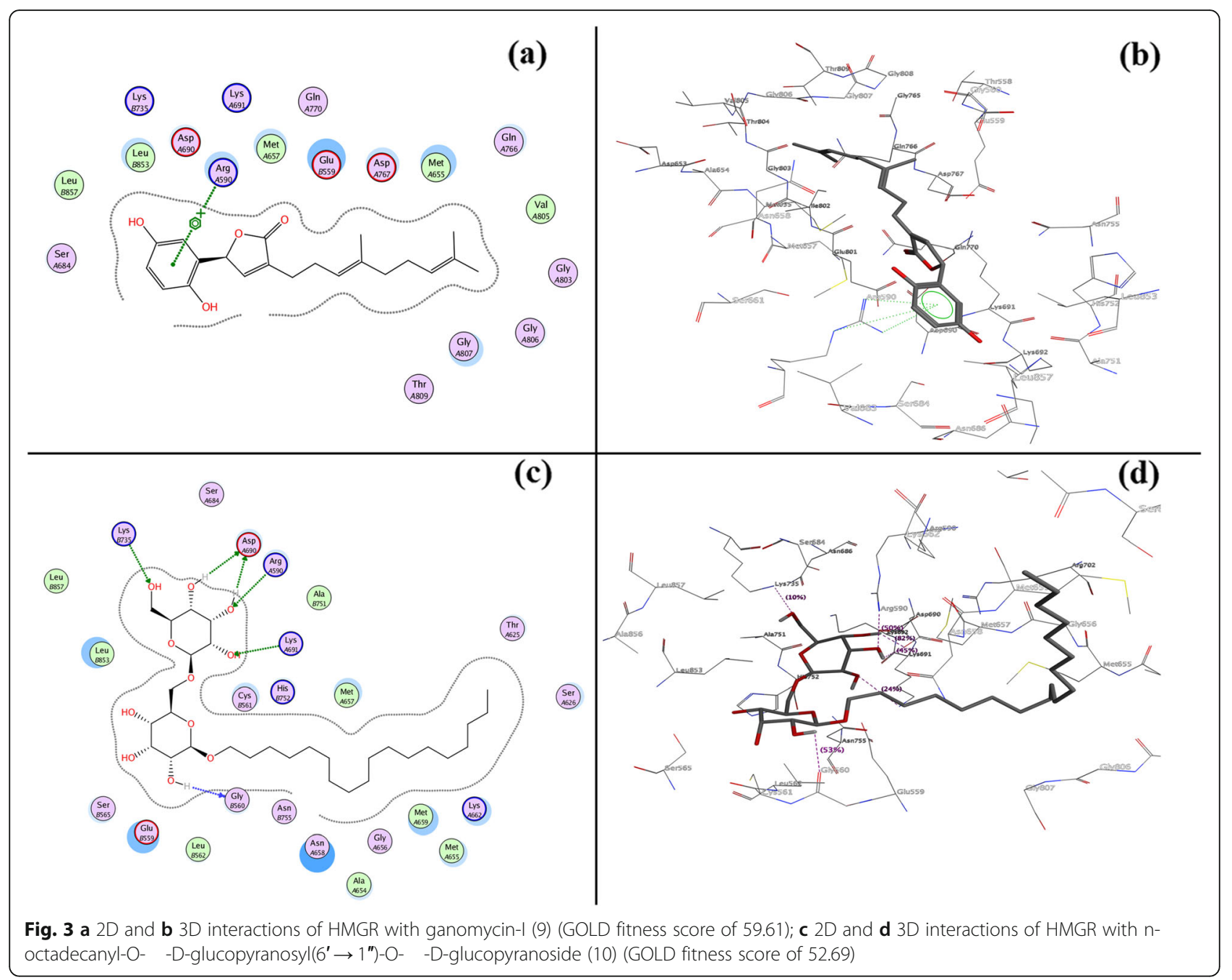

\section{Discussion}

Active plant-derived drugs can create a new era as therapeutic agents. Although this article is based on molecular docking of natural products already characterized, Table 9S shows crude extracts of natural sources that show significant inhibitory activity against $\mathrm{XO}$ and HMGR for broader coverage in the field. Molecular docking continues to hold great promise in the field of computer-based drug design. The higher the GOLD fitness score of ligands, the higher the binding capacity to protein residues [45]. Hydrogen bonding and hydrophobic interactions play an essential role in determining the binding affinity and stability of protein-ligand complexes $[54,55]$. Furthermore, the lower the protein-ligand complex's binding energy, the higher is its stability [56].

The GOLD fitness scoring of (1) and (3) was higher than commercially available XO inhibitors. Moreover, the GOLD fitness score of (4), (5), (6), and (7) are harmonious with that of commercial XO inhibitors. The binding energy of (2) and (3) was found lower than commercially available $\mathrm{XO}$ inhibitors illustrating its better stability. For instance, the inhibitory effect of the XO is probably due to the lodging of (1) in its active site via H-bonding with neighboring Glu 802, Asn 768, Ser 876, and Phe 914 amino acid residues and Pi-Pi interaction with Phe 914. From this interaction, the catalytic center of $\mathrm{XO}$ would undergo a conformational change and suppress the enzyme activity [57]. XO is a complex molybdoflavoprotein that produces ROS via reducing oxygen at the flavin center [58]. With the inhibition of XO, increased HDL levels have been reported in animal models [59]. Moreover, HDL is associated with reverse cholesterol transport and cholesterol efflux that prevents atherosclerosis and, ultimately, CVDs [60]. Moreover, the studies showed the superiority of non-purine analog of $\mathrm{XO}$ inhibitors over purine analogs regarding side effects and toxicity [61]. On account of this, the compounds 18 are non-purine analogs. Previously, (1) and (3) were shown with anticancer, anti-inflammatory, and antioxidant activities [62-65]. Thus, this is evident that XO 
inhibitors, used widely as the remedy of hyperuricemia, could be potential candidates for regulating body cholesterol levels.

Similarly, the binding affinity of (9) to enzyme active sites, via $\mathrm{H}$-bonding and $\mathrm{Pi}-\mathrm{Pi}$ interaction with Arg A590 amino acid residue, is higher than that of commercial inhibitors of HMGR. Moreover, compound (9), (10), and (11) showed lower binding energy than commercially available HMGR inhibitors, which further strengthens the stability of the protein-ligand complex thus formed. The probable mechanism is competitive inhibition via the binding of (9) and (10) at the active site of HMGR inhibiting natural substrate (HMG-CoA). This inhibition lowers the cholesterol levels in the ER and induces the transport of sterol regulatory element-binding proteins (SREBPs) to the Golgi body. These SREBPs express the genes of LDL receptors and speed up removing LDL and VLDL from plasma [31, 66]. Previously, (9) had been shown as HMGR and an $\alpha$-glucosidase inhibitor [67]. This showed that these secondary metabolites also bind effectively to enzymes like commercial drugs and could be potential inhibitors of $\mathrm{XO}$ and HMGR, respectively. Though the compounds (2) and (11)-(13) possess appropriate GOLD scores, they are not regarded as potential drugs owing to their toxicity on virtual screening.

In ADMET profiles, an intestinal absorption value above $30 \%$ signifies good absorption in the human intestine. The volume of distribution (VDss) is taken into consideration if the $\log V D s s$ value greater than 0.45 . The compounds with $\log \mathrm{BB}<-1$ are said to be poorly distributed to brain, while those having $\log \mathrm{BB}>0.3$ are potential to cross $\mathrm{BBB}$ $[49,68,69]$. The cytochrome P450 (CYP) plays a major role in drug metabolism with CYP (1A2, 2C9, 2C19, 2D6, and 3A4), mainly responsible for the biotransformation of greater than $90 \%$ of drugs in phase- 1 metabolism [70, 71]. However, among these P450 families, CYP3A4 is the focus part of this study [72]. The relationship between the rate of elimination of the drug and the drug concentration in the body is best described by total clearance [73]. Moreover, it is mandatory to examine the toxicity value based on parameters like ames toxicity, hepatotoxicity, and oral toxicity range because these play a critical role in the selection of drugs.

As discussed earlier, the studies suggest that XO inhibitors lessen the threat of major adverse cardiovascular events (MACE) [74]. With the availability of a handful of $\mathrm{XO}$ inhibitors in clinical use for treating hyperuricemia, the novel drugs addressing cardiac complications are demanding [75]. Recently, non-purine-like XO inhibitors have drawn significant attention, so they do not interfere with other facets of purine metabolism [52]. XO inhibitors could be equally useful for diabetic patients [75]. Although statins have been used widely for many decades as HMGR inhibitors, they are marked with muscular disorders, diabetes, liver diseases, etc. [31, 76]. Novel HMGR inhibitors are called for minimizing these side effects. However, the problems associated with natural secondary metabolites, such as their stability, solubility, and bioavailability, need to be considered to use them as therapeutic agents [77]. Furthermore, clinical trials, structural modifications, and biomimetic synthesis may lead to the discovery of promising inhibitors of HMGR and $\mathrm{XO}$, which could contribute to the treatment of hyperuricemia and lowering cholesterol.

\section{Conclusions}

The most potent natural inhibitors of the $\mathrm{XO}$ and HMGR are selected based on reported experimental $\mathrm{IC}_{50}$ values and show that these metabolites could be potent in lowering cholesterol levels. The molecular docking analysis shows that amentoflavone (1), 6paradol (3), and selgin (4) fit well in the binding site of $\mathrm{XO}$ and lower the catalytic activity of the enzyme by changing its conformation. The studies and evidence suggest that XO inhibitors could be potential in regulating cholesterol levels. Similarly, the binding affinity of ganomycin-I (9) and n-octadecanyl-O- $\alpha$-D-glucopyrano$\operatorname{syl}\left(6^{\prime} \rightarrow 1^{\prime \prime}\right)-O-\alpha-D$-glucopyranoside (10) are involved in arresting the cholesterol biosynthetic pathway. Thus, the shreds of evidence like experimental $\mathrm{IC}_{50}$ value, computational docking, in-silico pharmacokinetics, and toxicity analysis proclaim that natural products could be used to develop potential future drug candidates.

\section{Supplementary Information}

The online version contains supplementary material available at https://doi. org/10.1186/s12906-020-03162-5.

\footnotetext{
Additional file 1: Table 1S. Details about molecular docking platform. Table 2S. List of Targets showing the PDB ID, resolution and description of the proteins selected for docking with complexed inhibitor. Table $\mathbf{3 S}$ Active Site residues of HMG-CoA Reductase and Xanthine Oxidase. Table 4S. Molecular Properties of standard compounds and selected secondary metabolites. Table $\mathbf{5 S}$. Inhibition of HMGR reductase by secondary metabolites. Table $\mathbf{6 S}$. Inhibition of XO by secondary metabolites. Table 7S. Prediction of toxicity of secondary metabolites inhibiting metabolic enzymes using ProTox-II. Table 8S (a): ADMET properties of XO inhibitors by pKCSM server. Table $\mathbf{8 S}$ (b): ADMET properties of HMGR inhibitors by pKCSM server. Table $\mathbf{9 S}$. Crude natural product extracts showing the inhibitory activity against HMGR and XO. Table 10S. Gold Fitness score and Protein-Ligand Interactions of Protein ID: 1HWK, HMGCoA Reductase Inhibition, and Protein ID: 1N5X Xanthine Oxidase Inhibition. The Gold Fitness score, interacting residues, type of interaction, bond length between residues, and ligands are shown. Table 11S: Binding Free Energy calculations for $\mathrm{XO}$ with inhibitors using semi-empirical method. Table 12S: Binding Free Energy calculations for HMGR with inhibitors using semi-empirical method. Figure 1S. 2D (upper) and 3D (lower) interactions of HMG-CoA Reductase (PDB ID: 1HWK) with atorvastatin (Fitness score of 73.24). Figure 2S. 2D (upper) and 3D (lower) interactions of HMG-CoA Reductase with simvastatin (Fitness score of 56.81). Figure 3S. 2D (upper) and 3D (lower) interactions of HMG-CoA Reductase with lovastatin (Fitness score of 41.36). Fig. 4S. 2D (upper) and 3D (lower) interactions of HMG-CoA Reductase with pravastatin (Fitness score of 54.83). Fig. 5S. 2D (upper) and 3D (lower) interactions of Xanthine
} 
Oxidase (PDB ID: 1N5X) with febuxostat (Fitness score of 64.53). Fig. 6S. $2 \mathrm{D}$ (upper) and 3D (lower) interactions of Xanthine Oxidase with allopurinol (Fitness score of 46.16). Fig. 7S. 2D (upper) and 3D (lower) interactions of Xanthine Oxidase with probenecid (Fitness score of 57.75).

\section{Abbreviations}

ACAT-2: Acyl-CoA cholesterol acyltransferase 2; Al: Artificial intelligence; ANGPTL3: Angiopoietin-like protein 3; ATP: Adenosine triphosphate; BBB: Blood-brain barrier; CVDs: Cardiovascular diseases; CYP: Cytochrome P450; DGAT-2: Diglyceride acyltransferase 2; ER: Endoplasmic reticulum; GOLD: Genetic optimization for ligand docking; HDL: High-density lipoproteins; HMG-CoA: $\beta$-Hydroxy $\beta$-methylglutaryl-coenzyme A; HMGR: HMG-CoA reductase; IHD: Ischemic heart disease; kDa: Kilodalton; LDL: Low-density lipoprotein; MACE: Major adverse cardiovascular events; MOE: Molecular Operating Environment; NOS: Nitric oxide synthase; PCSK9: Proprotein convertase subtilisin kexin type 9; ROS: Reactive oxygen species; SREBPs: Sterol regulatory element-binding proteins; TC: Total cholesterol; TG: Triglyceride; TPSA: Total polar surface area; VLDL: Very lowdensity lipoprotein; WHO: World Health Organization; XO: Xanthine oxidase

\section{Acknowledgements}

We thank Mr. Sita Ram Phuyal, Mr. Purushottam Niraula, Mr. Karan Khadayat, and Mrs. Sonika Dawadi for their constructive suggestions.

\section{Authors' contributions}

$\mathrm{RM}, \mathrm{BRB}$, and $\mathrm{PB}$ analyzed the literature on $\mathrm{XO}$ and HMGR and interpreted data. SB performed the molecular docking experiments and was a major contributor in writing the manuscript. BRB, BA, GL, DKP, and NP drafted the manuscript. NP supervised the project and developed the concept. All authors have read and approved the final manuscript.

\section{Funding}

No

\section{Availability of data and materials}

The datasets used and/or analyzed during the current study are available from the corresponding author on reasonable request.

\section{Ethics approval and consent to participate}

Not applicable.

\section{Consent for publication}

The authors declare that there is no conflict of interest regarding the publication of this paper.

\section{Competing interests}

The authors declare that they have no competing interests.

\section{Author details}

${ }^{1}$ Central Department of Chemistry, Tribhuvan University, Kirtipur, Kathmandu, Nepal. ${ }^{2}$ Center for Drug Design and Molecular Simulation Division, Cancer Care Nepal and Research Center, Jorpati, Kathmandu, Nepal.

Received: 27 July 2020 Accepted: 23 November 2020

Published online: 01 January 2021

\section{References}

1. Joseph $\mathrm{P}$, et al. Reducing the global burden of cardiovascular disease, part 1: the epidemiology and risk factors. Circ Res. 2017;121(6):677-94. https:// doi.org/10.1161/CIRCRESAHA.117.308903..

2. "WHO," WHO, Raised Cholesterol. https://www.who.int/gho/ncd/risk_factors/ cholesterol_text/en/ (accessed 5 Jul 2020).

3. Pikuleva IA. Cholesterol-metabolizing cytochromes P450: implications for cholesterol lowering. Expert Opin Drug Metab Toxicol. 2008;4(11):1403-14. https://doi.org/10.1517/17425255.4.11.1403.

4. Repa JJ, Mangelsdorf DJ. The role of orphan nuclear receptors in the regulation of cholesterol homeostasis. Annu Rev Cell Dev Biol. 2000;16(1): 459-81. https://doi.org/10.1146/annurev.cellbio.16.1.459.
5. Weissglas-Volkov D, Pajukanta P. Genetic causes of high and low serum HDL-cholesterol. J Lipid Res. 2010;51(8):2032-57. https://doi.org/10.1194/jlr. R004739.

6. Fu J, et al. The gut microbiome contributes to a substantial proportion of the variation in blood lipids. Circ Res. 2015;117(9):817-24. https://doi.org/10. 1161/CIRCRESAHA.115.306807.

7. Liu J-P, Tang Y, Zhou S, Toh BH, McLean C, Li H. Cholesterol involvement in the pathogenesis of neurodegenerative diseases. Mol Cell Neurosci. 2010; 43(1):33-42. https://doi.org/10.1016/j.mcn.2009.07.013.

8. Yu X-H, Zhang D-W, Zheng X-L, Tang C-K. Cholesterol transport system: an integrated cholesterol transport model involved in atherosclerosis. Prog Lipid Res. 2019;73:65-91. https://doi.org/10.1016/j.plipres.2018.12.002..

9. Alvi SS, labal D, Ahmad S, Khan MS. Molecular rationale delineating the role of lycopene as a potent HMG-CoA reductase inhibitor: in vitro and in silico study. Nat Prod Res. 2016;30(18):2111-4. https://doi.org/10.1080/14786419. 2015.1108977.

10. Blumenthal RS. Statins: effective antiatherosclerotic therapy. Am Heart J. 2000;139(4):577-83. https://doi.org/10.1016/S0002-8703(00)90033-4.

11. Pirillo A, Norata GD, Catapano AL. LDL-cholesterol-lowering therapy. Berlin, Heidelberg: Springer Berlin Heidelberg; 2020.

12. Bays HE, Neff D, Tomassini JE, Tershakovec AM. Ezetimibe: cholesterol lowering and beyond. Expert Rev Cardiovasc Ther. 2008;6(4):447-70. https:// doi.org/10.1586/14779072.6.4.447

13. Mazidi M, Rezaie P, Karimi E, Kengne AP. The effects of bile acid sequestrants on lipid profile and blood glucose concentrations: a systematic review and meta-analysis of randomized controlled trials. Int J Cardiol. 2017; 227:850-7. https://doi.org/10.1016/j.jjcard.2016.10.011.

14. Giugliano RP, Sabatine MS. Are PCSK9 inhibitors the next breakthrough in the cardiovascular field? J Am Coll Cardiol. 2015;65(24):2638-51. https://doi. org/10.1016/j.jacc.2015.05.001.

15. Laufs $U$, et al. Efficacy and Safety of Bempedoic Acid in Patients With Hypercholesterolemia and Statin Intolerance. J Am Heart Assoc. 2019;8(7). https://doi.org/10.1161/JAHA.118.011662.

16. Rader DJ, Kastelein JJP. Lomitapide and Mipomersen: two first-in-class drugs for reducing low-density lipoprotein cholesterol in patients with homozygous familial hypercholesterolemia. Circulation. 2014;129(9):1022-32. https://doi.org/10.1161/CIRCULATIONAHA.113.001292.

17. Huff MW, Daugherty A, Lu H. "Atherosclerosis," in Biochemistry of Lipids, Lipoproteins and Membranes, Elsevier; 2016. p. 519-48.

18. Aziz N, Jamil RT. Biochemistry, Xanthine Oxidase. In: StatPearls. Treasure Island (FL): StatPearls Publishing; 2020.

19. Murrow JR. Statins, Diabetic Oxidative Stress and Vascular Tissue. In: Diabetes: Oxidative Stress and Dietary Antioxidants, Elsevier; 2014. p. 183-90.

20. Pacher $P$, Bátkai $S$, Kunos $G$. The Endocannabinoid system as an emerging target of pharmacotherapy. Pharmacol Rev. 2006;58(3):389-462. https://doi. org/10.1124/pr.58.3.2.

21. Battelli MG, Bolognesi A, Polito L. Pathophysiology of circulating xanthine oxidoreductase: new emerging roles for a multi-tasking enzyme. Biochim Biophys Acta (BBA) - Mol Basis Dis. 2014;1842(9):1502-17. https://doi.org/10. 1016/j.bbadis.2014.05.022.

22. Maiuolo J, Oppedisano F, Gratteri S, Muscoli C, Mollace V. Regulation of uric acid metabolism and excretion. Int J Cardiol. 2016;213:8-14. https://doi.org/ 10.1016/j.jijcard.2015.08.109.

23. Struthers A, Shearer F. Allopurinol: novel indications in cardiovascular disease. Heart. 2012;98(21):1543-5. https://doi.org/10.1136/heartjnl-2012302249.

24. Zdrenghea M, Sitar-Tǎut A, Cismaru G, Zdrenghea D, Pop D. Xanthine oxidase inhibitors in ischaemic heart disease. Cardiovasc J Afr. 2017;28(3): 201-4. https://doi.org/10.5830/CVJA-2016-068.

25. Devrim E, Ergüder IB, Özbek H, Durak I. High-cholesterol diet increases xanthine oxidase and decreases nitric oxide synthase activities in erythrocytes from rats. Nutr Res. 2008;28(3):212-5. https://doi.org/10.1016/j. nutres.2008.01.006

26. Saban-Ruiz J, Alonso-Pacho A, Fabregate-Fuente M, de la Puerta GonzalezQuevedo C. Xanthine oxidase inhibitor Febuxostat as a novel agent postulated to act against vascular inflammation. Anti-Inflamm Anti-Allergy Agents Med Chem. 2013;12(1):94-9. https://doi.org/10.2174/ 1871523011312010011.

27. Hansson GK, Hermansson A. The immune system in atherosclerosis. Nat Immunol. 2011:12(3):204-12. https://doi.org/10.1038/ni.2001. 
28. Mudau M, Genis A, Lochner A, Strijdom H. Endothelial dysfunction : the early predictor of atherosclerosis. Cardiovasc. J. Afr. 2012;23(4):222-31. https://doi.org/10.5830/CVJA-2011-068.

29. Istvan ES. Structural mechanism for statin inhibition of HMG-CoA Reductase. Science. May 2001;292(5519):1160-4. https://doi.org/10.1126/science. 1059344.

30. Miziorko HM. Enzymes of the mevalonate pathway of isoprenoid biosynthesis. Arch Biochem Biophys. 2011;505(2):131-43. https://doi.org/10. 1016/j.abb.2010.09.028.

31. Feingold KR. Cholesterol Lowering Drugs. In: Endotext. South Dartmouth (MA): MDText.com, Inc; 2020

32. Atanasov AG, et al. Discovery and resupply of pharmacologically active plant-derived natural products: a review. Biotechnol Adv. 2015;33(8):1582614. https://doi.org/10.1016/j.biotechadv.2015.08.001.

33. Linder T, et al. Design and Synthesis of a Compound Library Exploiting 5Methoxyleoligin as Potential Cholesterol Efflux Promoter. Molecules. 2020; 25(3):662. https://doi.org/10.3390/molecules25030662.

34. Burley SK, et al. RCSB protein data Bank: sustaining a living digital data resource that enables breakthroughs in scientific research and biomedical education: RCSB protein data Bank. Protein Sci. 2018;27(1):316-30. https:// doi.org/10.1002/pro.3331

35. Okamoto K, Eger BT, Nishino T, Kondo S, Pai EF, Nishino T. An extremely potent inhibitor of xanthine Oxidoreductase: CRYSTAL STRUCTURE OF THE ENZYME-INHIBITOR COMPLEX AND MECHANISM OF INHIBITION. J BiOl Chem. 2003:278(3TT):1848-55. https://doi.org/10.1074/jbc.M208307200.

36. Jiang S-Y, et al. Discovery of a potent HMG-CoA reductase degrader that eliminates statin-induced reductase accumulation and lowers cholesterol. Nat Commun. 2018:9(1):5138. https://doi.org/10.1038/s41467-018-07590-3.

37. Santi MD, et al. Xanthine oxidase inhibitory activity of natural and hemisynthetic flavonoids from Gardenia oudiepe (Rubiaceae) in vitro and molecular docking studies. Eur J Med Chem. Jan. 2018;143:577-82. https:// doi.org/10.1016/j.ejmech.2017.11.071.

38. Kwon E-K, et al. Flavonoids from the buds of Rosa damascena inhibit the activity of 3-Hydroxy-3-methylglutaryl-coenzyme a Reductase and angiotensin I-converting enzyme. J Agric Food Chem. 2010;58(2):882-6. https://doi.org/10.1021/jf903515f.

39. Guha R, Willighagen E. A survey of quantitative descriptions of molecular structure. Curr Top Med Chem. 2012;12(18):1946-56. https://doi.org/10.2174/ 156802612804910278.

40. Del Carpio CA, Takahashi Y, Sasaki S. A new approach to the automatic identification of candidates for ligand receptor sites in proteins: (I) search for pocket regions. J Mol Graph. 1993;11(1):23-9. https://doi.org/10.1016/ 0263-7855(93)85003-9.

41. Zhang J, et al. Eight new triterpenoids with inhibitory activity against HMGCoA reductase from the medical mushroom Ganoderma leucocontextum collected in Tibetan plateau. Fitoterapia. 2018;130:79-88. https://doi.org/10. 1016/j.fitote.2018.08.009.

42. da Silva VB, Taft CA, Silva CHTP. Use of virtual screening, flexible docking, and molecular interaction fields to design novel HMG-CoA Reductase inhibitors for the treatment of hypercholesterolemia ${ }^{\dagger}$. J Phys Chem A. 2008; 112(10):2007-11. https://doi.org/10.1021/jp075502e.

43. Jones $G$, Willett $P$, Glen RC, Leach AR, Taylor R. Development and validation of a genetic algorithm for flexible docking. J Mol Biol. 1997;267(3):727-48. https://doi.org/10.1006/jmbi.1996.0897.

44. Spassov VZ, Yan L. A fast and accurate computational approach to protein ionization. Protein Sci. 2008;17(11):1955-70. https://doi.org/10.1110/ps. 036335.108.

45. Pagadala NS, Syed K, Tuszynski J. Software for molecular docking: a review. Biophys Rev. 2017;9(2):91-102. https://doi.org/10.1007/s12551-016-0247-1.

46. Huey R, Morris GM, Olson AJ, Goodsell DS. A semiempirical free energy force field with charge-based desolvation. J Comput Chem. 2007;28(6): 1145-52. https://doi.org/10.1002/jcc.20634.

47. Peng $C_{\text {, et }}$ al. Improving the accuracy of predicting protein-ligand bindingfree energy with semiempirical quantum chemistry charge. Future Med Chem. 2019;11(4):303-21. https://doi.org/10.4155/fmc-2018-0207.

48. Uciechowska $U$, et al. Binding free energy calculations and biological testing of novel thiobarbiturates as inhibitors of the human NAD+ dependent histone deacetylase Sirt2. MedChemComm. 2012;3(2):167-73. https://doi. org/10.1039/C1MD00214G.

49. Pires DEV, Blundell TL, Ascher DB. pkCSM: predicting small-molecule pharmacokinetic and toxicity properties using graph-based signatures. J
Med Chem. 2015;58(9):4066-72. https://doi.org/10.1021/acs.jmedchem. 5 b00104.

50. Banerjee P, Eckert AO, Schrey AK, Preissner R. ProTox-II: a webserver for the prediction of toxicity of chemicals. Nucleic Acids Res. 46(W1):W257-63, 02 2018. https://doi.org/10.1093/nar/gky318.

51. Machhar J, Mittal A, Agrawal S, Pethe AM, Kharkar PS. Computational prediction of toxicity of small organic molecules: state-of-the-art. Phys Sci Rev. 2019;4(10). https://doi.org/10.1515/psr-2019-0009.

52. Luna G, Dolzhenko AV, Mancera RL. Inhibitors of xanthine oxidase: scaffold diversity and structure-based drug design. ChemMedChem. 2019;14(7):71443. https://doi.org/10.1002/cmdc.201900034.

53. Cao H, Hall J, Hille R. Substrate orientation and specificity in xanthine oxidase: crystal structures of the enzyme in complex with Indole-3acetaldehyde and guanine. Biochemistry. 2014;53(3):533-41. https://doi.org/ 10.1021/bi401465u.

54. Sakkiah S, Thangapandian S, Lee KW. Ligand-based virtual screening and molecular docking studies to identify the critical chemical features of potent Cathepsin D inhibitors: Pharmacophore-based identification of potent inhibitor of Cathepsin D. Chem Biol Drug Des. 2012;80(1):64-79. https://doi.org/10.1111/j.1747-0285.2012.01339.x.

55. Boobbyer DN, Goodford PJ, McWhinnie PM, Wade RC. New hydrogen-bond potentials for use in determining energetically favorable binding sites on molecules of known structure. J Med Chem. 1989;32(5):1083-94. https://doi. org/10.1021/jm00125a025.

56. Dolgonosov AM. The universal relationship between the energy and length of a covalent bond derived from the theory of generalized charges. Russ J Inorg Chem. 2017;62(3):344-50. https://doi.org/10.1134/S0036023617030068.

57. Lin S, Zhang G, Pan J, Gong D. Deciphering the inhibitory mechanism of genistein on xanthine oxidase in vitro. J Photochem Photobiol B. 2015;153: 463-72. https://doi.org/10.1016/j.jphotobiol.2015.10.022.

58. Šmelcerović $A$, et al. Xanthine oxidase inhibitors beyond allopurinol and febuxostat; an overview and selection of potential leads based on in silico calculated physico-chemical properties, predicted pharmacokinetics and toxicity. Eur J Med Chem. 2017;135:491-516. https://doi.org/10.1016/j. ejmech.2017.04.031.

59. J. Nomura et al., "Xanthine Oxidase Inhibition by Febuxostat Attenuates Experimental Atherosclerosis in Mice," Sci. Rep., vol. 4, no. 1, p. 4554, May 2015, doi: https://doi.org/10.1038/srep04554.

60. Rohatgi A, et al. HDL cholesterol efflux capacity and incident cardiovascular events. N Engl J Med. 2014;371(25):2383-93. https://doi.org/10.1056/ NEJMoa1409065.

61. Kumar R, Darpan SS, Singh R. Xanthine oxidase inhibitors: a patent survey. Expert Opin Ther Pat. 2011;21(7):1071-108. https://doi.org/10.1517/ 13543776.2011 .577417

62. Chung W-Y, Jung Y-J, Surh Y-J, Lee S-S, Park K-K. Antioxidative and antitumor promoting effects of [6]-paradol and its homologs. Mutat Res Toxicol Environ Mutagen. 2001;496(1-2):199-206. https://doi.org/10.1016/ S1383-5718(01)00221-2.

63. S. Bais and N. Abrol, "Review on Chemistry and Pharmacological Potential of Amentoflavone," vol. 6, no. 1, pp. 16-22, 2016, doi: https://doi.org/10.3923/ crn.2016.16.22

64. Dugasani S, Pichika MR, Nadarajah VD, Balijepalli MK, Tandra S, Korlakunta JN. Comparative antioxidant and anti-inflammatory effects of [6]-gingerol, [8]-gingerol, [10]-gingerol and [6]-shogaol. J Ethnopharmacol. 2010;127(2): 515-20. https://doi.org/10.1016/j.jep.2009.10.004.

65. Prasad S, Tyagi AK. Ginger and Its Constituents: Role in Prevention and Treatment of Gastrointestinal Cancer. Gastroenterology Research and Practice. 2015;08 https://www.hindawi.com/journals/grp/2015/142979/ (.

66. Goldstein JL, Brown MS. A century of cholesterol and coronaries: from plaques to genes to statins. Cell. 2015;161(1):161-72. https://doi.org/10. 1016/j.cell.2015.01.036.

67. Wang $\mathrm{K}$, et al. A novel class of a-glucosidase and HMG-CoA reductase inhibitors from Ganoderma leucocontextum and the anti-diabetic properties of ganomycin I in KK-A y mice. Eur J Med Chem. 2017;127:103546. https://doi.org/10.1016/j.ejmech.2016.11.015.

68. Clark DE. In silico prediction of blood-brain barrier permeation. Drug Discov Today. 2003;8(20):927-33. https://doi.org/10.1016/S1359-6446(03)02827-7.

69. Muehlbacher M, Spitzer GM, Liedl KR, Kornhuber J. Qualitative prediction of blood-brain barrier permeability on a large and refined dataset. J Comput Aided Mol Des. 2011;25(12):1095-106. https://doi.org/10.1007/s10822-0119478-1. 
70. Šrejber M, et al. Membrane-attached mammalian cytochromes P450: an overview of the membrane's effects on structure, drug binding, and interactions with redox partners. J Inorg Biochem. 2018;183:117-36. https:// doi.org/10.1016/j.jinorgbio.2018.03.002.

71. Ogu CC, Maxa JL. Drug interactions due to cytochrome P450. Proc Bayl Univ Med Cent. 2000;13(4):421-3.

72. Tornio A, Backman JT. Cytochrome P450 in Pharmacogenetics: An Update. Advances in Pharmacology. 2018;83, Elsevier:3-32.

73. Watanabe $R$, et al. Development of an in silico prediction system of human renal excretion and clearance from chemical structure information incorporating fraction unbound in plasma as a descriptor. Sci. Rep. 2019; 9(1):18782. https://doi.org/10.1038/s41598-019-55325-1.

74. Bredemeier $\mathrm{M}$, et al. Xanthine oxidase inhibitors for prevention of cardiovascular events: a systematic review and meta-analysis of randomized controlled trials. BMC Cardiovasc. Disord. 2018;18(1):24. https://doi.org/10. 1186/s12872-018-0757-9.

75. Pacher P, Nivorozhkin A, Szabó C. Therapeutic effects of xanthine oxidase inhibitors: renaissance half a century after the discovery of allopurinol. Pharmacol Rev. Mar. 2006;58(1):87-114. https://doi.org/10.1124/pr.58.1.6.

76. He Y, et al. Statins and Multiple Noncardiovascular Outcomes: Umbrella Review of Meta-analyses of Observational Studies and Randomized Controlled Trials. Ann Intern Med. 2018;169(8):543. https://doi.org/10.7326/ M18-0808

77. Coimbra M, et al. Improving solubility and chemical stability of natural compounds for medicinal use by incorporation into liposomes. Int J Pharm. 2011;416(2):433-42. https://doi.org/10.1016/j.jpharm.2011.01.056.

\section{Publisher's Note}

Springer Nature remains neutral with regard to jurisdictional claims in published maps and institutional affiliations.

Ready to submit your research? Choose BMC and benefit from:

- fast, convenient online submission

- thorough peer review by experienced researchers in your field

- rapid publication on acceptance

- support for research data, including large and complex data types

- gold Open Access which fosters wider collaboration and increased citations

- maximum visibility for your research: over $100 \mathrm{M}$ website views per year

At $\mathrm{BMC}$, research is always in progress.

Learn more biomedcentral.com/submissions 